\title{
Short communication: Milking order consistency of dairy cows in large Australian herds
}

\author{
D. S. Beggs, ${ }^{1}$ E. C. Jongman, P. H. Hemsworth, and A. D. Fisher \\ Animal Welfare Science Centre, Faculty of Veterinary and Agricultural Sciences, University of Melbourne, VIC 3010, Australia
}

\begin{abstract}
We used on-farm records from dairy infrastructure to examine the consistency of the milking order over 150 $\mathrm{d}$ in 5 Australian dairy herds that were milking more than 500 cows as a single group. Within a single day the difference in milking order rank position was less than 20 percentage points for $72 \%$ of cows. The correlation coefficient comparing milking rank position in the morning and afternoon was 0.72 , with the position of cows at the beginning and end of the milking order being more consistent than cows toward the middle of the milking order. Over a period of $150 \mathrm{~d}$, cows with a mean position in the first and last $20 \%$ of the milking order maintained their position more consistently than cows in the middle of the milking order. Milking position of cows between one month and the next was highly correlated $(\mathrm{r}=0.88)$. In large herds, subpopulations of cows are regularly milked toward the beginning and the end of the milking order. It is common for cows to be collected from the paddock as a group, to wait as a group in the dairy yard to be milked, and to return individually to the paddock or feed pad immediately after they have been milked. Thus, cows milked later in the milking order are likely to be away from the paddock for several hours longer than cows milked earlier in the milking order. This may affect their welfare though differences in time available for lying down, equality of pasture eaten, and time spent standing in the dairy yard.

Key words: milking order, dairy cow behavior
\end{abstract}

\section{Short Communication}

Large pasture-based dairy herds, where more than 500 cows are milked at a time, are a significant part of the Australian dairy industry, accounting for more than $35 \%$ of the approximately 1.65 million cows milked in

Received February 17, 2017.

Accepted August 21, 2017.

${ }^{1}$ Corresponding author: dbeggs@unimelb.edu.au
2014 (Dairy Australia, 2013; Beggs et al., 2015). On most large Australian dairy farms, cows graze pasture during the day, with supplementary feed provided in the form of concentrates fed in the dairy parlor during milking, and forages fed either in the paddock following milking or on a feed pad (an intermediate area between the exit of the dairy and the paddock). It is common for cows to be collected from the paddock as a group, to wait as a group in the dairy yard to be milked, and then individually return to the paddock or feed pad immediately following milking (Scott et al., 2014). Thus, cows milked later in the milking order are likely to be away from the paddock for longer than cows milked earlier in the milking order. This has a potential effect on cow health and welfare, particularly if the same cows are consistently milked toward the end of the milking order, as the mean duration of milking in large Australian dairy herds has been reported as exceeding $2.5 \mathrm{~h}$ (Beggs et al., 2015).

Consistency in entrance order of dairy cows to the milking parlor in groups of less than 300 cows has been demonstrated by several authors (Soffié et al., 1976; Rathore, 1982; Sauter-Louis et al., 2004; Botheras, 2006; Grasso et al., 2007; Berry and McCarthy, 2012; Polikarpus et al., 2015). Many factors have been shown to affect the milking position of individual dairy cows, including position in the social hierarchy (Rathore, 1982; Sauter-Louis et al., 2004); introduction of new animals to the herd (Soffié et al., 1976); stage of lactation (Rathore, 1982; Sauter-Louis et al., 2004); estrus (Scott Mitchell et al., 1996); lameness (Botheras, 2006); milk yield (Rathore, 1982; Berry and McCarthy, 2012); cell count or mastitis (Rathore, 1982; Berry and McCarthy, 2012; Polikarpus et al., 2015); genetics (Berry and McCarthy, 2012); and the presence of disease such as metritis and pneumonia (Polikarpus et al., 2015). The milking order (order in which cows are milked) is also related to the walking order (the order in which they leave the paddock; Sauter-Louis et al., 2004).

As herd size increases above 500 cows, it seems likely that sheer crowd size combined with the myriad of factors at play that affect milking order could make a stable milking order less likely. To our knowledge, the 
consistency of the milking order in larger herds has not been examined closely.

We examined the consistency of the milking order in 5 large Australian dairy herds. We assessed the relationship between milking position in the morning versus milking position in the afternoon; the relationship between mean milking position in one month versus milking position in the next month; and assessed whether variation in milking position was related to mean milking position itself.

To achieve this, 5 southwest Victorian seasonally calving dairy farms were identified that milked more than 500 cows twice a day as a single group in a rotary dairy and had specific infrastructure that recorded the time and milking position of each cow as they entered the milking platform (Identity, Jantec Systems, Geelong East, Victoria, Australia). The mean number of cows in the 5 milking herds during the study period were $525,595,654,657$, and 793 .

We chose a study period with the aim of minimizing the number of cows entering the herd to maximize the potential stability of the milking order. Two herds did not have any cows calve during the study period, 2 herds had less than 20 cows calve, and 1 herd had approximately 200 cows calve during the first 2 mo of the 5 -mo study period.

In these herds, as cows walked on to the dairy platform, the dairy infrastructure reads a microchip embedded in the ear tag of each cow and records the time and bail position of the cow within the rotary dairy. The process is not failsafe, and occasionally (generally less than $2 \%$ of cows at an individual milking) a tag is not read. Ranking methodology should be fairly robust against this, as occasional missing cows reduce the sample size a little but will not change the order or alter the rank position of the other cows in a meaningful way.

Daily milking records were extracted from each farm for approximately the same period of $150 \mathrm{~d}$ between August 2014 and January 2015. The individual periods varied by up to $14 \mathrm{~d}$ and were chosen to minimize cows entering or leaving the herd during the period and, thus, maximize the potential stability of the milking order. Records consisted of a separate file for each milking that contained individual cow records with the cow identification, calving date, age, time the cow entered the milking platform, and the platform bail position. The number of cows milked at each morning and evening was calculated, and the rank order (rank position) of each cow within each milking was calculated after accounting for empty bails where a cow did not enter the milking platform. A percentile rank position calculated for each cow milking using the formula rank percentile $=($ rank position $/$ cows milked +1$) \times 100$.
The potential to deviate from a rank percentile position decreases toward the beginning and the end of the milking order because the rank percentile positions are bounded by 0 and 100 . For example, the cow that enters the milking platform first can only change position in one direction. To examine the relationship between rank position and variation in rank position accounting for the effects of bounding by 0 and 100, a normal score (Dickinson Gibbons, 2006) was calculated for the rank percentile of each cow milked using the formula normal score $=\Phi^{-1}$ (rank percentile), where $\Phi^{-1}$ is the inverse cumulative normal distribution function. The difference in normal score places more emphasis on changes early (or late) in the milking order. For example, a cow that changes from rank percentile 1 to 6 is a change in rank percentile of 5 and a change in normal score of 0.67 , whereas changing positions from 47 to 52 is still a rank percentile change of 5 but a normal score change of 0.1 (Botheras, 2006).

To investigate the correlation between morning and afternoon rank percentile and normal score, a database was constructed that included all cow days where a cow was milked at both morning and afternoon milkings. Pearson Correlations were calculated using SPSS (IBM SPSS Statistics for Windows, Version 24.0. IBM Corp., Armonk, NY) to assess the correlation between position in the afternoon milking and position in the morning milking, age, and day of lactation.

Data were available for 483,887 cow-days where individual cows were recorded at both the morning and evening milking. Correlation between rank position at the morning and evening milkings is shown in Table 1. Overall, rank position in the morning and afternoon milking was strongly correlated $\left(\mathrm{R}^{2}=0.52\right)$, suggesting that $52 \%$ of the variation in position at the evening milking could be explained by position at the morning milking. We found no linear relationship between rank position and either DIM ( $\mathrm{r}<0.1, P<0.001)$ or age (r $<0.1, P<0.001)$. Using the normal score instead of the raw rank percentile did not change the interpretation $(r$

Table 1. The correlation between rank position at morning and afternoon milkings over a period of $150 \mathrm{~d}$

\begin{tabular}{lccc}
\hline Farm & $\begin{array}{c}\text { Pearson } \\
\text { correlation } \\
\text { coefficient }(\mathrm{r})\end{array}$ & $\begin{array}{c}\text { Coefficient of } \\
\text { determination } \\
\left(\mathrm{R}^{2}\right)\end{array}$ & $\begin{array}{c}\text { Significance } \\
(P \text {-value })\end{array}$ \\
\hline $\mathrm{A}$ & 0.72 & 0.52 & $<0.001$ \\
$\mathrm{~B}$ & 0.57 & 0.31 & $<0.001$ \\
$\mathrm{C}$ & 0.78 & 0.61 & $<0.001$ \\
$\mathrm{D}$ & 0.72 & 0.52 & $<0.001$ \\
$\mathrm{E}$ & 0.77 & 0.59 & $<0.001$ \\
Overall & 0.72 & 0.52 & $<0.001$ \\
\hline
\end{tabular}


Table 2. The percentage of cows on each farm that changed milking order rank percentile between the morning and evening milking

\begin{tabular}{lcccccc}
\hline $\begin{array}{l}\text { Difference in } \\
\text { rank percentile }\end{array}$ & Farm A & Farm B & Farm C & Farm D & Farm E & Mean \\
\hline $0-20$ & 70.5 & 65.9 & 76.7 & 70.3 & 74.2 & 71.9 \\
$21-40$ & 22.1 & 19.4 & 17.7 & 22.1 & 20.2 & 20.1 \\
$41-60$ & 6.1 & 9.8 & 4.7 & 6.4 & 4.8 & 6.2 \\
$61-80$ & 1.2 & 4.0 & 0.8 & 1.2 & 0.8 & 1.5 \\
$81-100$ & 0.2 & 1.0 & 0.1 & 0.1 & 0.1 & 0.3 \\
\hline
\end{tabular}

$=0.73, P<0.001)$, suggesting that there might be less variation at the beginning and end of the milking order.

For each cow-day, the difference between rank percentile position at the morning and evening milking was calculated. For each farm, we calculated the proportion of cow-days where the rank position changed by 0 to 20, 21 to 40,41 to 60,61 to 80 , or greater than $80 \%$. A typical milking in Australian dairy herds that milk more than 500 cows takes 158 to 186 min (Beggs et al., 2015). Thus, cows milked within the same $20 \%$ range (quintile) would likely be milked within 30 to $40 \mathrm{~min}$ of each other, and cows that are consistently milked 1 quintile later in the milking order might be expected to be out of the paddock for 60 to 80 min longer per day. The proportion of cows that changed position by each quintile was calculated using the CrossTabs function in SPSS.

Table 2 shows the percentage of cows that changed position from the morning to the evening milking by increments of $20 \%$ for each farm. Approximately $70 \%$ of cows were milked within 20 percentage points (which approximates to being milked within the same $30-40$ min block) and less than $2 \%$ of cows were milked more than $60 \%$ apart.

Table 3 shows the percentage of cows that changed position from the morning to the evening milking by increments of $20 \%$ for cows that appeared in each quintile of the milking order at the morning milking. Interestingly, approximately $80 \%$ cows in the first or last quintile changed milking position by less than $20 \%$, compared with less than $70 \%$ of cows in the middle quintiles. This suggests that cows at the beginning and end of the milking order are more likely to have a consistent position within a day than cows in the middle. This is at odds with what one might expect if cow position was not correlated, as cows at the ends of the milking order have more scope for change - a cow in the middle quintile cannot change position by more than 2 quintiles. These data suggest that, within a day, individual cows will tend to be milked at a similar time with respect to the beginning of the milking session.

To examine the consistency of the milking order over a longer period, milking order from month to month, mean and variance of rank percentile and normal score were calculated for each cow that had more than 20 observations in both months for the months of September and October 2014. Pearson correlations were used to assess the correlation between the first month and subsequent months. To assess the consistency in position of individual cows, the proportion of cows where the mean milking position was within 10 and 20 rank percentile positions was calculated.

Data were available for 2,239 cows that had more than 20 observations in both September and October. These months were chosen because the milking herds were relatively stable during these periods, with less than 10 cows calving in 4 of the herds and a maximum of $1 \%$ of the herd size calving on any day in the fifth herd. Figure 1 shows the mean rank position of cows in September versus October during the study period. The positions were highly correlated $(\mathrm{r}=0.88)$, suggesting that cows can maintain their relative position

Table 3. Percentage of cows where the afternoon milking order rank percentile changed by differing amounts from the morning milking

\begin{tabular}{lrrrrr}
\hline & \multicolumn{5}{c}{ Milking order rank percentile at the morning milking } \\
\cline { 2 - 6 } $\begin{array}{l}\text { Difference in } \\
\text { rank percentile }\end{array}$ & $0-20$ & $21-40$ & $41-60$ & $61-80$ & $81-100$ \\
\hline $0-20$ & 77.8 & 68.3 & 64.0 & 69.6 & 80.0 \\
$21-40$ & 13.8 & 24.0 & 30.7 & 21.2 & 10.7 \\
$41-60$ & 6.2 & 6.6 & 5.3 & 7.7 & 5.2 \\
$61-80$ & 1.9 & 1.1 & & & 3.1 \\
$81-100$ & 0.4 & & & & 1.0 \\
\hline
\end{tabular}


in the milking order over a prolonged period of at least several weeks.

To assess whether the variation in milking position was related to mean milking position itself, the mean and variance of rank percentile were calculated for each cow for all milkings within the 150-d study period, where cows were present in both the first and last week of the period and had at least 200 observations during the period. The mean variance for cows with mean rank positions in each quintile from 0 to 100 were compared using ANOVA with significance assessed using Tamhane's T2 method in SPSS (that does not assume equal variances).

Data were available for 3,332 cows across the 5 farms. The variance and standard deviation for rank position classified according to mean rank percentile are shown in Table 4. The standard deviations of 12 and 14 for cows whose rank position is within the first and last quintiles suggests that these cows would be within 24 and 28 percentage points of their rank position $95 \%$ of the time.

Figure 2 shows that the variance of rank percentile varies with rank percentile, with variance being lower toward the beginning and end of the milking order, and higher toward the middle of the milking order. These

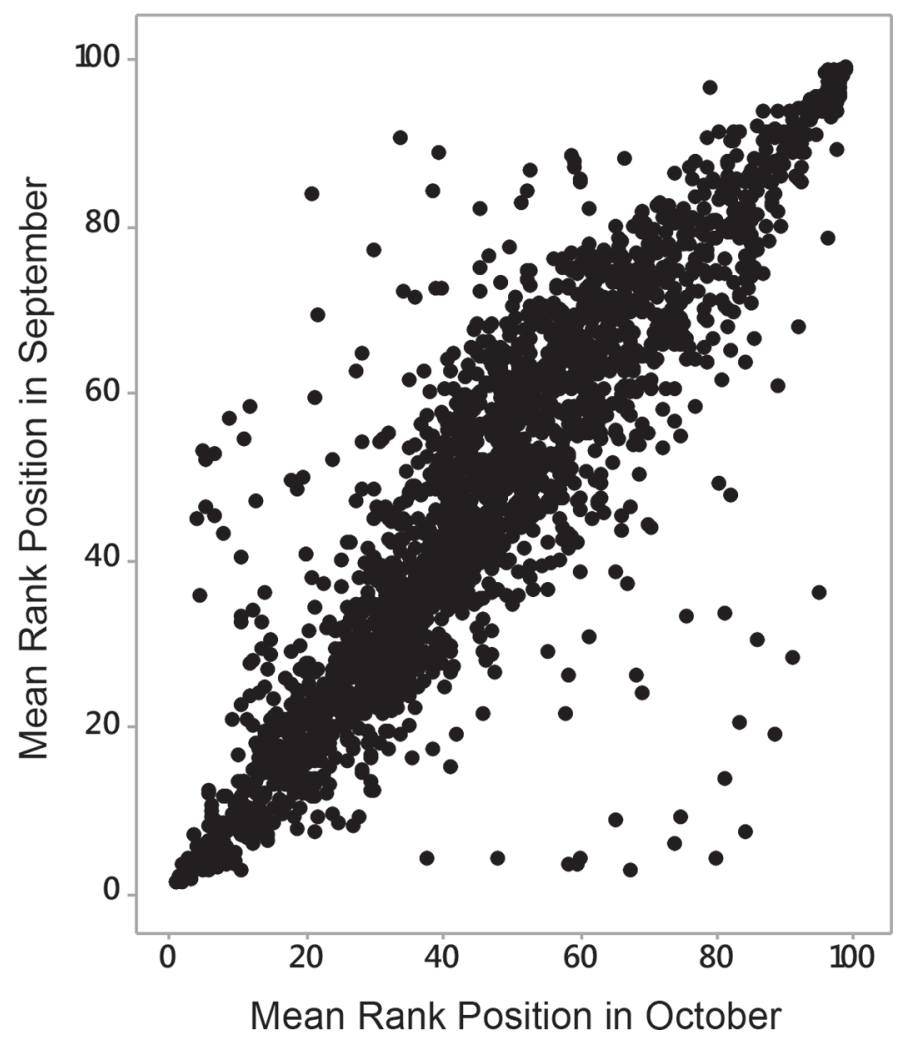

Figure 1. Mean rank position of cows in the milking order over 2 consecutive months (September and October).
Table 4. Consistency of milking order rank position over $150 \mathrm{~d}$ for cows with differing mean milking order rank percentiles over the same period

\begin{tabular}{lcc}
\hline $\begin{array}{l}\text { Mean rank } \\
\text { position }\end{array}$ & $\begin{array}{c}\text { Mean variance } \\
\text { of rank position }\end{array}$ & $\begin{array}{c}\text { Mean SD of } \\
\text { rank position }\end{array}$ \\
\hline $0-20$ & $144^{\mathrm{a}}$ & 12.0 \\
$21-40$ & $387^{\mathrm{b}}$ & 19.7 \\
$41-60$ & $512^{\mathrm{c}}$ & 22.6 \\
$61-80$ & $394^{\mathrm{b}}$ & 19.8 \\
$81-100$ & $199^{\mathrm{d}}$ & 14.1 \\
Total & 389 & 19.7 \\
\hline
\end{tabular}

$\overline{\mathrm{a}-\mathrm{d}}$ Means within a column without a common superscript differ significantly $(P<0.05)$.

data suggest that cows toward the beginning and end of the milking order are more consistent in their positions over time. Despite the wide range of factors that have been shown to affect the milking order of individual cows, we showed that consistency of milking order can be a feature of cows in large herds.

Our results are broadly similar to others. Several studies in smaller herds have reported similar consistency of milking order. Botheras (2006) studied daily electronic records from a single herd, where up to 391 cows were milked on a single day. Correlations between the milking orders of any 2 milkings were very high (on average, $\mathrm{r}=0.8-0.9$ ), even for milkings up to 6 mo apart. In 10 New Zealand herds, with an average group size of 183, Sauter-Louis et al. (2004) reported

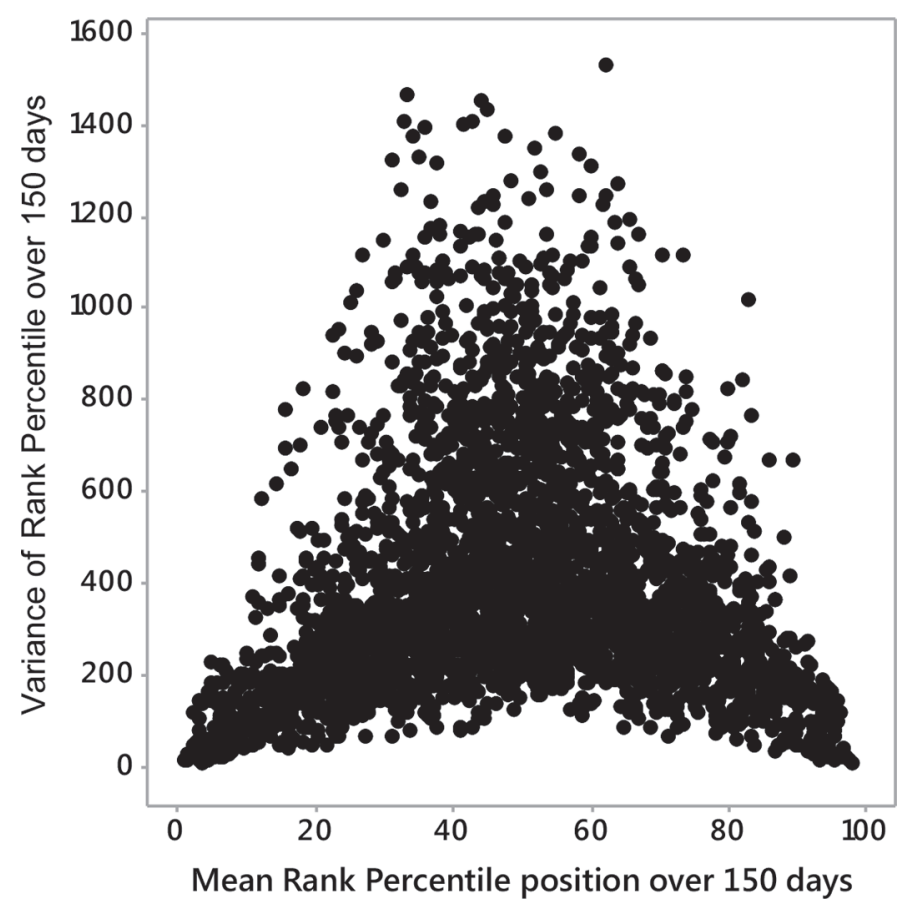

Figure 2. Mean rank percentile position in the milking order versus variance over $150 \mathrm{~d}$. 
Cronbach's $\alpha$ coefficients for milking order $>0.9$, with increasing walking order stability as the season progressed. A study of Irish herd-testing records, which examined genetic and nongenetic factors affecting milking order in nearly 2,000 herds ranging in size from 40 to 250 cows, showed that the repeatability of the milking order within test-day, within lactation, and across lactations was $0.63,0.51$, and 0.47 , respectively (Berry and McCarthy, 2012). A point of difference in our results is the higher consistency found for cows that are regularly toward either end of the milking order compared with those normally toward the middle. This is important because we have established that in larger herds there will likely be subpopulations of cows that are regularly milked later in the milking order. We did not measure the effect of this on individual cows, but it is interesting to speculate as to why this might be important.

One possible consequence of being milked later in the milking order is a reduction in the time available for lying down. High-producing dairy cattle on pasture typically spend about 9 to $11 \mathrm{~h}$ of the day lying down (Singh et al., 1993; Phillips and Rind, 2002; Botheras, 2006). The frequency and duration of lying behavior are probable indicators of cow comfort, and considerable evidence exists that restricting lying behavior reduces animal welfare outcomes (Metz, 1985; Fisher et al., 2002; Cooper et al., 2007). Thus, for those cows in large herds where milking times are prolonged, lying times may be reduced. Indeed, cows held in a holding pen for $2 \mathrm{~h}$ before milking to replicate prolonged waiting times had shorter lying times than cows that were milked and returned immediately to pasture (Botheras, $2006)$; this is worthy of further investigation.

A second possible consequence of being late in the milking order is nutritional. A study of Australian dairy cows (Scott et al., 2014) showed that milking order can affect the quality of pasture eaten. In 1 herd of just over 300 cows, where milking time took approximately $105 \mathrm{~min}$, serial measurements of pasture quality were made as cows entered the paddock following milking. Cows that arrived first to the paddock ingested pasture with greater $\mathrm{CP}$ (19 vs. 15\%) and lower ADF (26 vs. $30 \%$ ) than those arriving last, with $70 \%$ of the pasture (relative to postgrazing mass) being consumed before the last cow entered the paddock (Scott et al., 2014).

A third possible consequence of being later in the milking order relates to the extra time spent standing in the dairy yard before milking rather than time away from the paddock. The surface on which cows walk can affect the prevalence of lameness and the experience for cows that are lame (Sauter-Louis et al., 2004; Kremer et al., 2007; von Keyserlingk et al., 2009; Cook et al., 2016). Depending on the dairy yard surface and the condition of the paddock, the effect of being at the beginning or end of the milking order might be positive or negative in terms of animal welfare.

Our data suggest it is likely in large herds that there will be subpopulations of cows that are regularly milked toward the beginning and the end of the milking order. In cases where milking time lasts for $3 \mathrm{~h}$ or more (and cows are milked twice a day), potential exists for some cows to regularly spend 6 or more hours per day than their herdmates in the dairy yard waiting to be milked, standing on concrete and away from pasture. Whether that time is spent usefully ruminating, or whether it has implications for production (perhaps because of a variation in grass quality or quantity) or animal welfare (perhaps because of reduced time available to lie down or increased lameness as a result of standing on concrete), warrants further investigation.

\section{ACKNOWLEDGMENTS}

The authors thank the Victorian Department of Economic Development Jobs Transport and Resources (Melbourne, Victoria, Australia) and Dairy Australia Ltd. (Melbourne, Victoria, Australia) for their support of this project. This project was also supported through an Australian Government Research Training Program Scholarship. The assistance of Kym Butler (University of Melbourne) with some statistical advice was much appreciated as was the contribution of the farmers who provided their information.

\section{REFERENCES}

Beggs, D. S., A. D. Fisher, E. C. Jongman, and P. E. Hemsworth. 2015. A survey of Australian dairy farmers to investigate animal welfare risks associated with increasing scale of production. J. Dairy Sci. 98:5330-5338. https://doi.org/10.3168/jds.2014-9239.

Berry, D. P., and J. McCarthy. 2012. Genetic and non-genetic factors associated with milking order in lactating dairy cows. Appl. Anim. Behav. Sci. 136:15-19. https://doi.org/10.1016/j.applanim 2011.11.012.

Botheras, N. A. 2006. The behaviour and welfare of grazing dairy cows (Bos taurus): Effects of time away from pasture. $\mathrm{PhD}$ thesis. University of Melbourne, Melbourne, Australia.

Cook, N. B., J. P. Hess, M. R. Foy, T. B. Bennett, and R. L. Brotzman. 2016. Management characteristics, lameness, and body injuries of dairy cattle housed in high-performance dairy herds in Wisconsin. J. Dairy Sci. 99:5879-5891. https://doi.org/10.3168/jds.2016 -10956 .

Cooper, M. D., D. R. Arney, and C. J. C. Phillips. 2007. Two- or fourhour lying deprivation on the behavior of lactating dairy cows. J. Dairy Sci. 90:1149-1158. https://doi.org/10.3168/jds.S0022 -0302(07)71601-6.

Dairy Australia. 2013. Australian Dairy Industry Focus 2013. Dairy Australia, Melbourne, Australia.

Dickinson Gibbons, J. 2006. Normal scores tests. Encycl. Stat. Sci. 8:1-5. https://doi.org/10.1002/0471667196.ess1829.pub2.

Fisher, A., G. Verkerk, C. Morrow, and L. Matthews. 2002. The effects of feed restriction and lying deprivation on pituitary-adrenal axis regulation in lactating cows. Livest. Prod. Sci. 73:255-263.https:// doi.org/10.1016/S0301-6226(01)00246-9. 
Grasso, F., G. De Rosa, F. Napolitano, A. Di Francia, and A. Bordi. 2007. Entrance order and side preference of dairy cows in the milking parlour. Ital. J. Anim. Sci. 6:187-194. https://doi.org/10 .4081/ijas.2007.187.

Kremer, P. V., S. Nueske, A. M. Scholz, and M. Foerster. 2007. Comparison of claw health and milk yield in dairy cows on elastic or concrete flooring. J. Dairy Sci. 90:4603-4611. https://doi.org/10 .3168/jds.2006-549.

Metz, J. 1985. The reaction of cows to a short-term deprivation of lying. Appl. Anim. Behav. Sci. 13:301-307.

Phillips, C. J. C., and M. I. Rind. 2002. The effects of social dominance on the production and behavior of grazing dairy cows of fered forage supplements. J. Dairy Sci. 85:51-59. https://doi.org/ 10.3168/jds.S0022-0302(02)74052-6.

Polikarpus, A., T. Kaart, H. Mootse, G. De Rosa, and D. Arney. 2015. Influences of various factors on cows' entrance order into the milking parlour. Appl. Anim. Behav. Sci. 166:20-24. https://doi.org/ 10.1016/j.applanim.2015.02.016.

Rathore, A. 1982. Order of cow entry at milking and its relationships with milk yield and consistency of the order. Appl. Anim. Ethol. $8: 45-52$.

Sauter-Louis, C. M., R. N. Chesterton, and D. U. Pfeiffer. 2004. Behavioural characteristics of dairy cows with lameness in Taranaki,
New Zealand. N. Z. Vet. J. 52:103-108. https://doi.org/10.1080/ 00480169.2004.36414.

Scott, B. A., A. Camacho, H. Golder, J. Molfino, K. L. Kerrisk, I. Lean, and S. C. Garcia. 2014. The nutritive value of pasture ingested by dairy cows varies within a herd. Pages 343-346 in Proceedings of the 5th Australasian Dairy Science Symposium. Australasian Dairy Science Symposium, Hamilton, New Zealand.

Scott Mitchell, R., R. A. Sherlock, and L. A. Smith. 1996. An investigation into the use of machine learning for determining oestrus in cows. Comput. Electron. Agric. 15:195-213. https://doi.org/10 .1016/0168-1699(96)00016-6.

Singh, S. S., W. Ward, K. Lautenbach, J. Hughes, and R. Murray. 1993. Behaviour of first lactation and adult dairy cows while housed and at pasture and its relationship with sole lesions. Vet. Rec. 133:469-474. https://doi.org/10.1136/vr.133.19.469.

Soffié, M., G. Thines, and G. De Marneffe. 1976. Relation between milking order and dominance value in a group of dairy cows. Appl. Anim. Ethol. 2:271-276.

von Keyserlingk, M. A., J. Rushen, A. M. de Passillé, and D. M. Weary. 2009. Invited review: The welfare of dairy cattle-key concepts and the role of science. J. Dairy Sci. 92:4101-4111. https:// doi.org/10.3168/jds.2009-2326. 